\title{
Equivalência de Estímulos e Estratégias de Intervenção para Crianças com Dificuldade de Aprendizagem
}

\author{
Raquel Maria de Melo \\ Patrícia Serejo \\ Universidade de Brasília
}

\begin{abstract}
RESUMO
O paradigma de equivalência de estímulos foi utilizado como referencial para a elaboração e implementação de estratégias de intervenção individualizada para duas crianças que apresentavam dificuldade na alfabetização. As crianças participaram de programas de ensino de leitura de palavras com sílabas simples e complexas da língua portuguesa. Atividades lúdicas que envolviam ler e escrever foram realizadas em cada sessão antes e depois dos programas de ensino. As crianças aprenderam a ler as palavras de ensino com precisão. O desempenho nas tarefas de leitura e construção de palavras de recombinação melhorou com a exposição aos programas de ensino e às atividades lúdicas. $\mathrm{O}$ aumento gradual na precisão do repertório verbal em tarefas com palavras, frases e pequenos textos, observado assistematicamente durante as atividades lúdicas, sugere o efeito das estratégias de intervenção não só nos repertórios diretamente ensinados, mas também em comportamentos que envolvem diferentes modalidades de leitura e escrita. Estes resultados mostram o potencial de intervenções planejadas de acordo com o paradigma de equivalência para estabelecer condições para a ampliação do repertório verbal inicial do aprendiz e o ensino de unidades verbais maiores.
\end{abstract}

Palavras-chave: equivalência de estímulos; leitura; escrita.

\begin{abstract}
Stimulus Equivalence and Intervention Strategies for Children With Learning Disabilities

Based on the stimulus equivalence paradigm, we planned and implemented an individualized intervention for two 7- and 8 years old girls with learning disabilities. They were exposed to reading programs that included simple and complex Portuguese words. Ludic reading and spelling activities were conducted before and after the teaching program in each section. As a result, the children learned how to read the training words. Their performance on reading and spelling activities with generalization words increased with the reading intervention and the ludic activities. The gradual increase in accuracy of verbal performance in tasks with words, phrases and brief stories, observed sporadically during the ludic activities, suggests that there was an effect of the intervention strategies not only on the repertoire that was explicitly trained but also on new modalities of writing and reading. Interventions based on the stimulus equivalence paradigm give us conditions to extend an individual's verbal repertoire and also for teaching complex verbal units.
\end{abstract}

Keywords: stimulus equivalence; reading; spelling.

O objetivo do processo de alfabetização é a aquisição de competências para ler e escrever de maneira fluente e com compreensão, o que implica a capacidade de emitir os desempenhos de: ler palavras simples e complexas da língua, ler frases e pequenos textos; escrever palavras e frases em tarefas de ditado e cópia; e responder por escrito ou oralmente a questões sobre histórias ouvidas, acontecimentos ou informações lidas em textos, o que evidencia a compreensão (de Souza, de Rose, Hanna, Calcagno \& Galvão, 2004; Hanna, Melo \& Albuquerque, 1999). Entretanto, muitas crianças apresentam dificuldade de aprendizagem e/ou adquirem parcialmente os comportamentos definidos como objetivo da alfabetização, o que compromete a aprendizagem posterior de conteúdos acadêmicos e prejudica o desenvolvimento social e emocional da criança (Marinotti, 1997; Nunes, 1990). Ainda, dificuldade nas etapas iniciais da aprendizagem de leitura e escrita e suas consequências estão associadas a altos índices de repetência e evasão nos primeiros anos de escolarização formal ${ }^{1}$. 
Conhecimentos procedentes de pesquisas em Análise do Comportamento podem contribuir para a compreensão do processo de aquisição de leitura e escrita e ser utilizados como referenciais para o planejamento do atendimento de crianças que apresentam dificuldade de aprendizagem durante o período de alfabetização. No contexto de um atendimento individualizado, previamente à elaboração de estratégias de intervenção, as dificuldades de aprendizagem são avaliadas a partir de uma descrição detalhada das relações funcionais que envolvem o comportamento alvo (Meyer, 1997). Analisar funcionalmente a leitura e a escrita implica considerá-las, inicialmente, como parte de uma contingência de três termos, sendo necessário identificar as situações antecedentes, ou estímulos, diante dos quais ler e escrever ocorrem e o efeito que tais comportamentos produzem no comportamento de outras pessoas ou no ambiente físico.

Outra contribuição potencial da Análise do Comportamento é procedente de estudos sobre equivalência de estímulos. De acordo com o paradigma de equivalência de estímulos, o repertório de um indivíduo alfabetizado pode ser analisado como uma rede de desempenhos verbais interligados (de Rose, de Souza \& Hanna, 1996; Stromer, Mackay \& Stoddard, 1992). Ler e escrever não se restringem, portanto, a comportamentos unitários de uma determinada topografia (e.g., ler em voz alta; escrita manuscrita), mas envolvem modalidades distintas de desempenhos (e.g., nomear palavras impressas; selecionar a figura correspondente a cada palavra impressa, montar palavras a partir de letras ou sílabas separadas). Os diferentes desempenhos que compõem a rede de relações podem ser adquiridos mediante o procedimento de emparelhamento com o modelo, comumente utilizado para ensinar discriminações condicionais. Tarefas típicas do processo de alfabetização constituem exemplos de discriminação condicional tais como: o ensino de correspondência entre palavra ditada-figura e de palavra ditada-palavra impressa, relações $\mathrm{AB}$ e $\mathrm{AC}$, respectivamente, representadas na Figura 1 pelas linhas contínuas. $\mathrm{O}$ ensino de relações condicionais pode resultar em novos desempenhos, não explicitamente ensinados, denominados de desempenhos emergentes, e dar origem a classes de estímulos equivalentes (Sidman, 1994; Sidman \& Tailby, 1982). Estímulos de modalidades diferentes podem ser considerados equivalentes quando controlam um comportamento operante comum (e.g., dizer bola diante da figura de uma bola, da palavra escrita BOLA e de símbolos em Braille referentes à bola) e quando se verificam entre os elemen- tos da classe três propriedades: reflexividade (BB e $\mathrm{CC})$, simetria $(\mathrm{BC})$ e transitividade $(\mathrm{CB})$, representadas na Figura 1 por setas tracejadas.

A análise da rede de relações permite identificar os desempenhos que o aluno já domina e aqueles que precisam ser ensinados e/ou fortalecidos, a partir dos quais novos desempenhos podem emergir (Sidman, 1971; Sidman \& Tailby, 1982). Ao realizar uma análise mais cuidadosa, verifica-se que tais repertórios verbais dependem de outras habilidades, ou prérequisitos, que fazem parte das sequências de respostas envolvidas na leitura e escrita (e.g., posicionar corretamente o texto impresso, diferenciar material impresso de outros estímulos visuais, executar os movimentos necessários para desenhar as letras do alfabeto). É importante ressaltar que um processo de intervenção deve prever, paralelamente, o ensino dessas habilidades para crianças que ainda não as adquiriram ou executam-nas parcialmente ou de maneira imprecisa.

Os resultados de pesquisas sobre equivalência têm contribuído para a compreensão de variáveis relevantes para a aquisição de leitura e escrita e para a caracterização de um modelo comportamental da leitura com compreensão (de Rose, 1993; Sidman, 1994). Isto sugere o potencial deste referencial para a elaboração de estratégias de intervenção para crianças que apresentam dificuldades de aprendizagem durante a alfabetização (e.g., de Rose e cols. 1996; Melchiori, de Souza \& de Rose, 2000). Como exemplo pode ser citado o estudo de Rose e cols. (1996), que consistiu em ensinar os desempenhos de selecionar palavras impressas e figuras correspondentes a palavras ditadas (relações AB e AC) e montar palavras impressas apresentadas como modelo a partir de suas letras (pareamento de identidade ao modelo impresso com resposta construída ou cópia com resposta construída $\mathrm{CF}$ ). As crianças foram capazes de selecionar palavras impressas correspondentes a figuras e vice-versa $(\mathrm{BC}$ e CB) e ler as palavras impressas (CD), desempenhos que não foram ensinados diretamente. Ao longo do programa, a leitura de palavras novas, formadas pela recombinação de sílabas ou fonemas das palavras de ensino, aumentou gradualmente (e.g., ler pipa após o ensino de apito e pato). A leitura de palavras novas evidencia controle por unidades menores (sílabas, grafemas e fonemas) que compõem as palavras de ensino e constitui-se em um desempenho básico (ou pré-requisito) para a leitura fluente (Matos, Hubner \& Peres, 1997; Skinner,1957).

O objetivo deste estudo consistiu em avaliar o efeito de um procedimento de intervenção individuali- 
zada, fundamentada nos estudos sobre equivalência de estímulos, nos repertórios de leitura e escrita de duas crianças que apresentavam dificuldades na fase de alfabetização. Programas de ensino de leitura desenvolvidos em contextos de pesquisa foram utilizados nas sessões de atendimento conjuntamente com atividades lúdicas. O planejamento das atividades lúdicas foi realizado a partir da avaliação dos repertórios descritos na rede de relações (Figura 1) e do desempenho de cada criança ao longo dos programas de ensino.

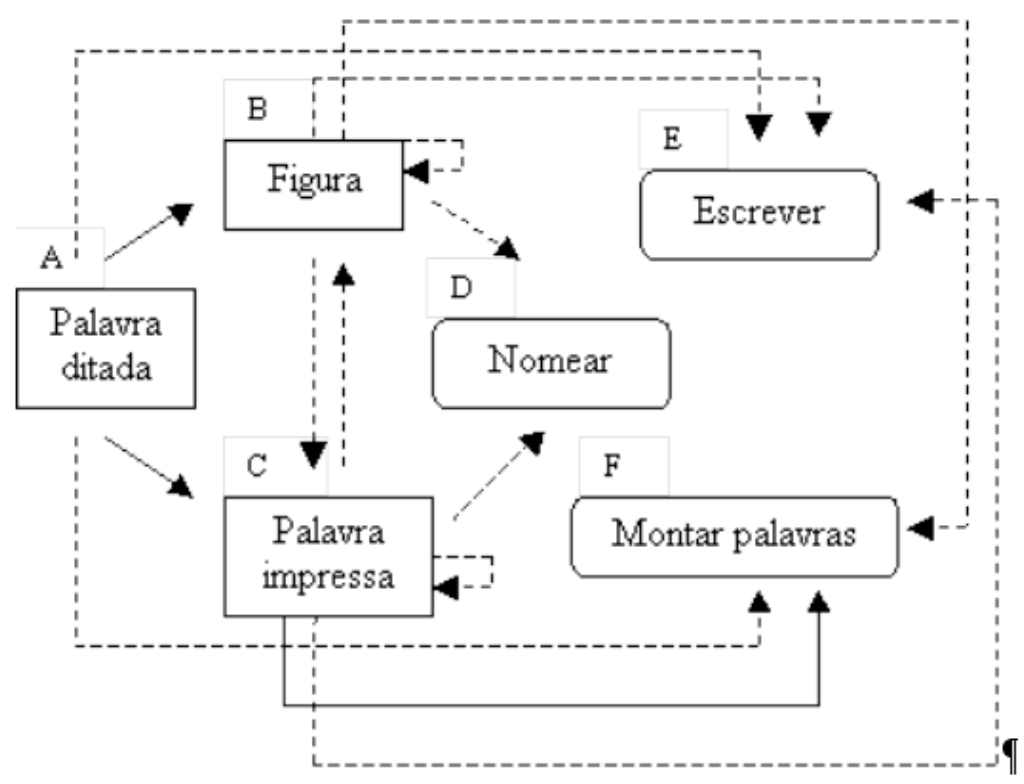

Figura 1. Diagrama esquemático da rede de relações condicionais envolvidas nos repertórios de leitura e escrita (adaptado do diagrama proposto por Stromer, Mackay \& Stoddard, 1992). As setas apontam do conjunto de estímulos modelo para 0 conjunto de comparações (e.g., $\mathrm{AB}, \mathrm{AC}$ ) ou do conjunto de estímulos para o desempenho emitido (e.g., $\mathrm{BD}, \mathrm{AE}$ ). As linhas contínuas indicam relações ensinadas e as linhas tracejadas, relações testadas ou que emergem sem serem explicitamente ensinadas (e.g., $\mathrm{BC}$ e CB). As setas que partem e retornam ao mesmo retângulo representam relações de identidade (CC, BB) entre os elementos de um conjunto de estímulos.

\section{MÉTODO}

\section{Participantes}

Foram atendidas duas crianças, do sexo feminino, encaminhadas pelo serviço de psicologia pediátrica de um hospital público. A participante KER (8 anos e 3 meses) tinha história de repetência na $1^{\mathrm{a}}$ série do Ensino Fundamental ${ }^{2}$ e LET (7 anos e 8 meses) apresentava dificuldade de aprendizagem dos repertórios de leitura e escrita.

\section{Local, materiais e equipamentos}

As sessões foram realizadas em uma sala destinada ao atendimento individual, equipada com mesas, cadeiras, um computador PC com monitor de 14", teclado e mouse, brinquedos, livros infantis, materiais escolares (e.g., lápis de cor, tesoura, cola, borracha) e palitos de madeira $(1,5 \times 13,5 \times 0,2 \mathrm{~cm})$ com letras do alfabeto coladas em uma de suas extremidades.

\section{Procedimento}

Foram realizadas sessões de atendimento individual, uma vez por semana, durante 18 meses. O atendimento compreendeu quatro etapas: (a) avaliação do repertório de entrada, (b) programa de ensino de leitura de palavras com sílabas simples, (c) de palavras com sílabas complexas, e (d) de frases e pequenos textos. As atividades lúdicas faziam parte das sessões de ensino de leitura de palavras simples e complexas.

\section{Avaliação do repertório de entrada}

Esta etapa consistiu de uma única sessão de atendimento individualizado. Inicialmente, para facilitar a interação e avaliar a identificação de estímulos iguais e diferentes, a criança foi convidada a brincar de dominó de figuras. Posteriormente, foi avaliada a nomeação de vogais e consoantes, leitura de palavras simples e complexas. Cartões com letras, sílabas ou palavras eram apresentados, um a um, e a criança era soli- 
citada a dizer o que estava escrito em cada um deles. Caso a criança se recusasse a ler ou respondesse "não sei" por cinco vezes consecutivas, a avaliação era interrompida.

\section{Programa de ensino de leitura de palavras simples}

Foi utilizada uma versão modificada e informatizada do programa de de Rose e cols. (1996), a qual foi desenvolvida por Rosa Filho, de Souza, de Rose, Fonseca e Hanna (1998). O programa, organizado em quatro unidades com passos de ensino e de avaliação, ensinava um total de 51 palavras nas quais eram utilizadas todas as vogais e 14 consoantes do alfabeto. As palavras eram constituídas por duas ou três sílabas, compostas por consoante e vogal (e.g., tomate) ou apenas por vogal (e.g., apito). Em cada unidade, treinavam-se as relações entre palavra ditada e figura (AB), entre palavra ditada e palavra impressa (AC) e a cópia com resposta construída (CF) e avaliavam-se as relações entre figura e palavra impressa e vice-versa (BC e CB), a leitura (CD) e ditado com resposta construída (pareamento ao modelo auditivo com resposta construída - AF). Palavras novas, compostas pela recombinação das letras ou das sílabas de palavras de ensino, eram avaliadas nas modalidades de leitura e de ditado. Após a Unidade 4, foi realizada uma avaliação final de leitura e ditado com palavras de ensino e de recombinação.

As respostas corretas eram sempre seguidas por sons programados pelo computador (e.g., aplausos, tons musicas, toques de campainha) e por reforçadores sociais fornecidos pelo instrutor (elogios e comentários sobre o progresso da criança). Os erros nas tentativas de ensino resultavam em comentário verbal programado pelo computador (e.g., "Não, não é!") e repetição da tentativa até que a criança respondesse corretamente. Erros nas tentativas de avaliação resultavam na apresentação da tentativa seguinte.

Para avançar de um passo de ensino para outro, a criança deveria ser capaz de ler todas as palavras ensinadas no passo. A escrita manuscrita (AE, BE e CE) não foi ensinada diretamente, mas foi verificada ao longo do programa em atividades lúdicas, posteriormente descritas.

\section{Programa de ensino de leitura de palavras complexas}

O programa (similar ao de de Rose, de Souza, Rossito \& de Rose, 1992) era composto por 52 passos de ensino de palavras complexas, que se caracterizavam por apresentar uma dentre três categorias de dificuldades da língua portuguesa. As dificuldades ensi- nadas foram: seis encontros consonantais (e.g., porta, escova, vento, pulga, tigre, diploma), quatro dígrafos (e.g., caqui, foguete, chuva, ninho) e três consoantes cujos sons são normalmente representados por outra letra, denominada como som diferente (e.g., exame, taça, tigela). Para cada dificuldade foi ensinada a leitura de 16 palavras, em quatro passos, utilizando o procedimento de exclusão (Dixon, 1977). Uma tentativa de ensino consistia na apresentação de duas palavras impressas, uma que a criança já sabia ler e outra possuía em sua composição a dificuldade a ser ensinada. A tarefa consistia em solicitar que a criança apontasse uma das palavras (de ensino ou conhecida) e, a seguir, que lesse a outra (conhecida ou de ensino). A leitura das palavras era avaliada antes (pré-teste) e depois (pósteste) da etapa de ensino de cada passo, com a apresentação de palavras de ensino e de recombinação. A criança somente avançava no programa quando nomeava corretamente as palavras de ensino do passo. Antes de cada passo era realizado um ditado (AE) para avaliar a escrita manuscrita das palavras de ensino e de recombinação apresentadas no passo anterior.

Respostas corretas nas etapas de ensino e de avaliação eram sempre seguidas por reforçadores sociais. Os erros, apenas nas etapas de ensino, resultavam em retorno à tentativa anterior ao erro ou na apresentação de dicas adicionais (e.g., "Este pedaço parece com o início da palavra clima" - com ênfase na pronúncia da sílaba inicial. "Agora tente ler esta palavra" - instrutor apontava, por exemplo, para a palavra declive). Nas avaliações, os erros não produziam consequência diferencial.

Ao longo das sessões também foi necessário ensinar a pronúncia correta das palavras utilizando-se estratégias tais como: apresentação do modelo correto, exagero na pronúncia (e.g., letra $\underline{\mathrm{r}}$ entre vogal e consoante - porta), a leitura pausada ou escandida (e.g., es - ti - lin - gue) e a modelagem da produção de sons (e.g., ensinar a posição correta da língua para produzir os sons tle em atleta e bli em neblina).

\section{Atividades Lúdicas}

Eram realizadas em dois momentos durante cada sessão, no início e após a exposição a cada passo dos programas de ensino de leitura de palavras simples ou complexas. Ao escolher as atividades, optou-se por aquelas que favoreciam a participação ativa da criança, criavam situações para emitir os desempenhos identificados na rede de relações e oportunidades para aprender desempenhos relevantes para a leitura e escrita, mas não explicitamente ensinados nos programas de ensino. Foram priorizadas atividades que proporcionavam exposição simultânea à palavra ditada e 
à sua forma impressa correspondente, a fim de facilitar a aquisição de correspondências som - texto com letras, sílabas e palavras. Para garantir respostas corretas, a complexidade das atividades aumentou gradualmente ao longo das sessões. No início, eram apresentadas atividades com dicas, tais como a leitura de palavras apresentadas juntamente com a respectiva figura e a cópia de palavras a partir de suas letras ou sílabas (cópia com resposta construída). Posteriormente, a leitura de palavras impressas e a escrita em situação de ditado eram realizadas sem a presença de dicas adicionais. Foram utilizadas diferentes atividades lúdicas, adaptadas ao repertório inicial de cada criança e ao desempenho nos programas de ensino. $\mathrm{O}$ instrutor fornecia as orientações necessárias à execução de cada atividade e mantinha interação constante com a criança, elogiando desempenhos corretos e parciais, e orientando-a a tentar fazer, da melhor maneira possível, o que era solicitado, e fornecendo dicas, tais como gestos ou apresentação dos sons iniciais da palavra. A seguir, são apresentados exemplos de atividades lúdicas utilizadas durante as sessões de atendimento, categorizadas de acordo com os desempenhos verbais descritos na Figura 1.

a) Ligar figuras com palavras (figura - palavra impressa; $\mathrm{BC}$ ): Em uma folha contendo duas colunas, uma com figuras e a outra com palavras, a criança era solicitada a ligar cada figura à palavra impressa correspondente. Após concluir a tarefa solicitava-se a leitura de cada palavra (CD).

b) Palavra-cruzada (figura - escrita manuscrita; $\mathrm{BE}$ ): A tarefa consistia em nomear as figuras diante de cada linha e/ou coluna da palavra-cruzada (BD) e, posteriormente, escrever as letras para compor as palavras correspondentes a cada figura (BE). Uma variação desta tarefa consistia em apresentar, oralmente, descrições de objetos ou animais para a criança adivinhar antes de escrever a palavra no local adequado (e.g., Animal que faz buraco na terra para se esconder; resposta correta - tatu).

c) Cortar, colar e copiar (palavra impressa - escrita manuscrita; CE): Após a nomeação, pelo instrutor, de cada uma das palavras impressas em um cartão, a criança deveria repeti-la pausadamente (AD), cortar suas partes (sílabas), colorir as sílabas com cores diferentes, colar as partes em sequência para formar a palavra em uma folha de papel (CF) e copiá-la (CE).

d) Ditado (palavra ditada - escrita manuscrita; AE): As palavras de ensino e de recombinação de um determinado passo de ensino eram pronunciadas uma a uma pelo instrutor e a criança deveria escrevê-las em uma folha de papel. e) Montar palavras a partir de suas letras (cópia com resposta construída; $\mathrm{CF}$ ): $\mathrm{O}$ instrutor mostrava cartões com diferentes palavras impressas, uma após a outra, dizia o nome da palavra e a seguir removia cada cartão. A criança deveria montar cada uma das palavras a partir de letras individuais apresentadas em palitos de madeira (CF) e dispostos de maneira aleatória sobre a mesa. Concluída a montagem da palavra, o instrutor reapresentava o cartão com a palavra impressa e pedia para a criança conferir com a palavra montada, letra a letra da esquerda para a direita. Se estivesse correto, era solicitada a nomeação da palavra (CD). Caso fosse identificado algum erro na montagem da palavra, solicitava-se a sua correção.

f) Compor palavras ditadas (ditado com resposta construída; AF): A criança deveria montar a palavra ditada pelo instrutor a partir de letras individuais apresentadas em palitos dispostos sobre a mesa. Era fornecida, por exemplo, a seguinte instrução, por exemplo: "Monte a palavra bola" e solicitada a nomeação das letras e da palavra montada (CD): "Que letra você pegou?" "Que palavra você montou?".

g) Bingo de palavras (palavra impressa - nomeação; CD): A tarefa da criança consistia em sortear uma palavra dentre várias inseridas em um saco plástico, ler a palavra selecionada (CD) e assinalar a palavra em uma cartela com várias palavras $(\mathrm{CC}$ - identidade).

\section{Programa de ensino de leitura de frases e pequenos textos}

Esta etapa ocorreu concomitantemente ao programa de ensino de leitura de palavras complexas. Foram planejadas atividades que incluíam também as palavras simples previamente ensinadas. Gradualmente, as tarefas passaram a envolver frases curtas (unidades verbais maiores) contendo substantivos, artigos, conjunções, preposições e verbos nos tempos verbais presente, passado e futuro simples. Posteriormente, foram utilizados pequenos textos em tarefas de leitura com solicitação de respostas oral e escrita de compreensão do texto impresso. Foram utilizadas, inicialmente, perguntas de compreensão cujas respostas estavam contidas literalmente no texto. De maneira gradativa, nas sessões seguintes eram formuladas perguntas que envolviam, além de compreensão, a opinião da criança. Também foi ensinada a leitura oral com entonação adequada à pontuação de frases e textos. Foram desenvolvidas nesta etapa do atendimento as seguintes atividades:

a) Montar frase a partir das palavras isoladas (CF) e ler a frase (CD). A tarefa consistia em apresentar 
palavras individuais e solicitar a sua leitura. A seguir, pedia-se para a criança montar uma frase com as palavras. Marcadores de início (letra maiúscula) e término das frases (ponto final) foram utilizados como dicas. Por exemplo, dadas as palavras sapo, $\underline{\mathrm{O}}$, rio., pula $\mathrm{e}$ $\underline{\text { no, a frase seria } \mathrm{O} \text { sapo pula no rio. }}$

b) Leitura de frases (CD): $O$ instrutor mostrava uma frase impressa e solicitava que a criança a lesse em voz alta. Caso a leitura fosse realizada de forma pausada, era solicitada uma nova leitura. A seguir, o instrutor fazia perguntas para verificar se a criança tinha compreendido o que acabou de ler. Dado a frase, O tamanco da Camila é branco, perguntava-se, por exemplo: "Qual a cor do tamanco da Camila?".

c) Leitura de livros (CD): Foi utilizado um procedimento similar ao descrito em de Souza e cols. (2004). A criança era solicitada a ler as frases contidas em cada página de livros de histórias infantis ilustrados. Os livros continham poucas páginas, frases curtas e em letras grandes, e as ilustrações, geralmente, forneciam pistas sobre o que estava escrito. Ao término da leitura de cada metade do livro, pedia-se para a criança contar a história com suas próprias palavras.

d) História e perguntas: A tarefa consistia em ler (CD), em voz alta, a história e a seguir responder perguntas relativas às informações presentes no texto.
Após responder cada pergunta oralmente, a criança deveria escrever a resposta no espaço adequado.

\section{RESULTADOS}

$\mathrm{Na}$ avaliação do repertório de entrada, as duas crianças participaram ativamente do jogo de dominó de figuras, seguiram as regras, e nomearam corretamente as figuras. Nas tarefas que envolviam letras e palavras, as crianças nomearam apenas as vogais e algumas consoantes e copiaram com precisão palavras impressas. Na tarefa de ditado (na ausência do modelo impresso) verificou-se escrita correta apenas de partes de palavras simples (duas vogais ou uma sílaba).

No programa de ensino de leitura de palavras simples, a precisão do desempenho das crianças foi alta em todas as unidades, variando de 83 a $100 \%$ de acerto, tanto nas tentativas de ensino de pareamento entre palavras ditadas e palavras impressas como nas tentativas de cópia com resposta construída, e ocorreu repetição apenas de dois passos para LET. Escores altos (média 95\% e variação de 76 a 100\% de acerto) também foram observados nos testes que avaliavam a formação de classes de equivalência (pareamento de palavra impressa com figura - $\mathrm{CB}$ e de figura com palavra impressa $-\mathrm{BC}$ ).

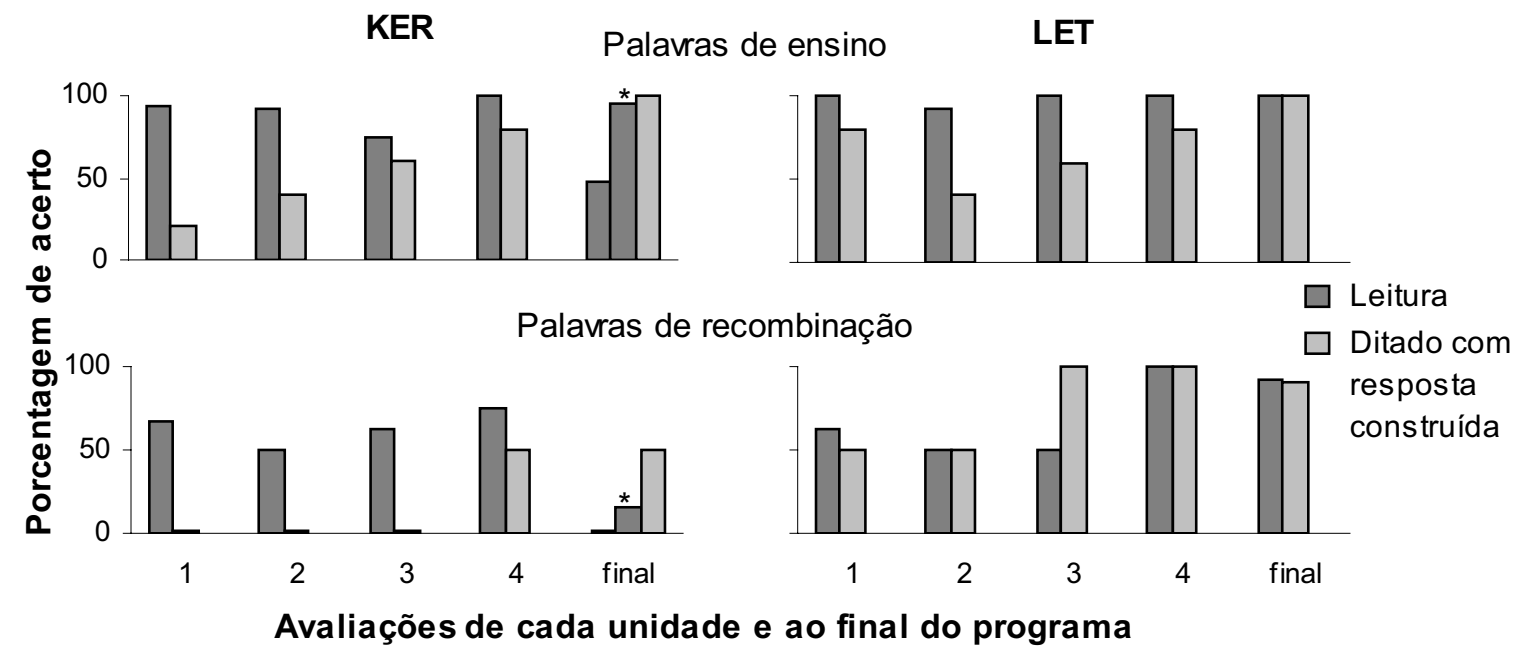

Figura 2. Porcentagem de acerto nas avaliações de leitura e de ditado com resposta construída de cada unidade e ao final do programa de ensino de leitura de palavras simples para as palavras de ensino e de recombinação. 0 asterisco ( ${ }^{*}$ ) indica a segunda exposição da participante KER à Avaliação Final.

A Figura 2 mostra a porcentagem de acerto nas avaliações de leitura e de ditado com resposta construída de cada unidade e ao final do programa de ensino de leitura de palavras simples para as palavras de ensino (gráficos superiores) e de recombinação (gráfi- cos inferiores). As colunas com asterisco representam os dados obtidos por KER na segunda exposição da Avaliação Final. Essa repetição ocorreu devido aos baixos índices de acerto alcançados na primeira exposição. A leitura das palavras de ensino foi superior a 
$70 \%$, para as duas crianças, com exceção de KER na primeira exposição da Avaliação Final. Na tarefa de ditado com resposta construída, os resultados para palavras de ensino foram crescentes ao longo das unidades, atingindo $100 \%$ de acerto na Avaliação Final para as duas crianças.

Em relação às palavras de recombinação, KER obteve desempenho entre 50 e $75 \%$ de acerto na leitura ao longo das unidades de ensino e $15 \%$ de acerto na segunda exposição da Avaliação Final. A construção de palavras de recombinação em situação de ditado emergiu na Unidade 4, sendo observado $50 \%$ de acerto nessa unidade e na Avaliação Final.

Nas duas primeiras unidades, LET obteve, para palavras de recombinação, aproximadamente $50 \%$ de acerto em tarefas de leitura e de ditado com resposta construída. Na Unidade 3, a leitura se manteve em $50 \%$ e o desempenho no ditado com resposta construída aumentou para $100 \%$ de acerto. Na Unidade 4 e na Avaliação Final, os resultados de leitura e de ditado com resposta construída foram superiores a $90 \%$ de acerto.

O desempenho das duas crianças no programa de ensino de leitura de palavras complexas é apresentado na Figura 3. As porcentagens de acerto de leitura das palavras de ensino (gráficos superiores) e das palavras de recombinação (gráficos da porção inferior) são apresentadas para cada um dos quatro passos de ensino das três categorias de palavras com sílabas com- plexas (encontro consonantal, dígrafo e som diferente). Para KER, observa-se que ao longo dos passos de uma mesma categoria de dificuldade, a leitura melhorou progressivamente nas avaliações realizadas antes de cada passo (pré-teste - círculo vazio) e atingiu porcentagens de acerto entre $90-100 \%$ na Avaliação Final (pós-teste - círculo cheio). Padrão semelhante de desempenho no pré-teste foi observado para KER na leitura das palavras de recombinação. Entretanto, as porcentagens de acerto no pós-teste tenderam a se concentrar em torno de 50 a $75 \%$. LET alcançou resultados variados no pré-teste de leitura de palavras de ensino: de 50 a $100 \%$ de acerto para palavras com encontro consonantal, de 80 a $100 \%$ para palavras com dígrafo, e de 25 a $75 \%$ de acerto para palavras com som diferente. No pós-teste, o desempenho foi superior a $95 \%$ para todas as categorias de palavras complexas. Na leitura de palavras de recombinação LET apresentou resultados que variaram no pré-teste de 40 a $100 \%$ de acerto, com tendência crescente para o desempenho no pós-teste, que variou de 75 a $100 \%$ de acerto.

Deve-se ressaltar que LET foi exposta apenas a dois dos quatro passos previstos para oito dificuldades (dois encontros consonantais, quatro dígrafos e dois sons diferentes) em função da alta precisão na leitura das palavras de ensino e de recombinação nas avaliações realizadas no final dos passos das primeiras cinco dificuldades ensinadas.

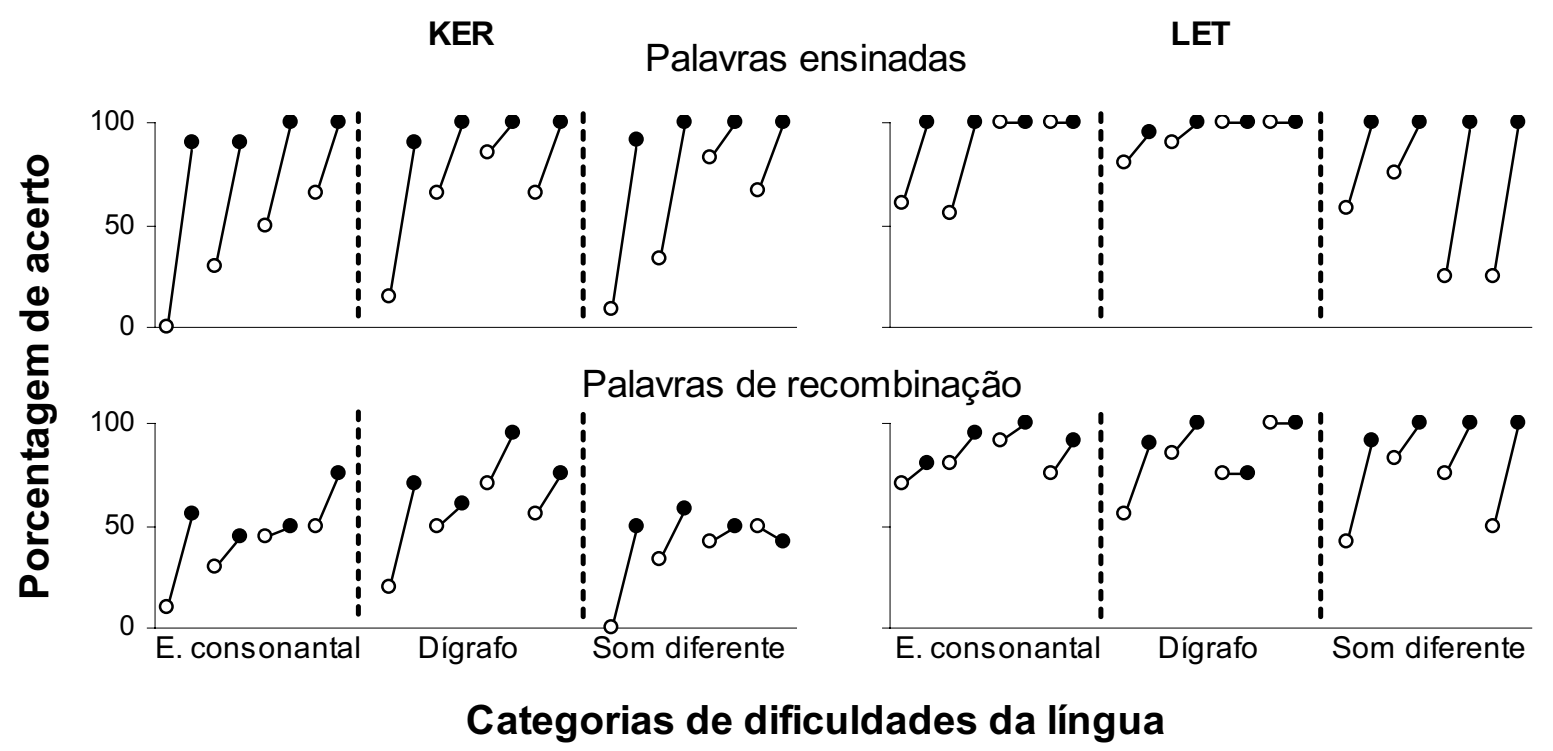

Figura 3. Porcentagem de acerto das palavras de ensino e de recombinação nas avaliações de leitura realizada antes (préteste - círculos vazios) e depois (pós-teste - círculos cheios) de cada um dos quatro passos de ensino das três diferentes categorias de dificuldades da língua: encontro consonantal, dígrafo e som diferente. 
No ditado de palavras complexas, realizado na sessão posterior ao passo de ensino, as crianças apresentaram uma porcentagem alta de acerto na escrita manuscrita das palavras de ensino e de recombinação, variando de 89 a $93 \%$. Os erros, em geral, envolviam omissão ou troca de uma letra (e.g., Teblete - troca da letra "a" por "e"; catiga - omissão da letra "n").

\section{DISCUSSÃO}

Os resultados apresentados sugerem que o paradigma de equivalência pode ser utilizado como referencial na elaboração de estratégias de intervenção individualizada que visam maximizar o processo de aquisição dos repertórios verbais complexos que caracterizam a leitura e a escrita. Ao final do atendimento, as crianças demonstraram competências para ler e escrever de maneira fluente e com compreensão evidenciadas por desempenhos como: relacionar palavra ditada com palavra impressa e vice-versa, leitura de palavras de ensino e de recombinação formadas por sílabas simples e complexas e escrita em tarefas de ditado manuscrito e de ditado com resposta construída. Estes resultados replicam os dados de estudos que utilizaram programas de ensino de leitura (de Rose \& cols., 1996; de Rose \& cols., 1992) e de cópia com resposta construída (Hanna, de Souza, de Rose \& Fonseca, 2004; Hanna e cols., 2002). Adicionalmente, pode-se sugerir o efeito dos programas de ensino de palavras simples e complexas e das tarefas lúdicas na aquisição de repertórios com unidades verbais maiores do que a palavra, tais como a leitura de frases e pequenos textos e a produção de respostas oral e escrita a perguntas sobre histórias lidas.

A forma como o atendimento foi planejado permitiu avaliar o efeito global das estratégias de intervenção nos comportamentos de ler e escrever. O delineamento de sujeito único permitiu comparar o desempenho de cada uma das duas crianças com história de dificuldade de aprendizagem no período de alfabetização em dois momentos: antes e após os procedimentos de intervenção. Este delineamento foi escolhido em função do contexto aplicado em que ocorreu o estudo e do repertório limitado das crianças para acompanhar as atividades de sala de aula que demandavam ler e escrever. A avaliação do efeito isolado das atividades lúdicas em comparação com os programas de ensino de leitura, já investigados na literatura sobre equivalência de estímulos, exigiria a realização de comparações entre grupos de participantes ou na introdução das atividades lúdicas em momentos diferentes da intervenção, o que poderia estender ainda mais os atendimentos e estaria além dos objetivos do atendimento proposto.

Os programas de ensino de leitura, juntamente com tarefas no formato de brincadeiras, que requeriam modalidades diferentes das respostas de ler e escrever, foram eficazes para a aprendizagem com um mínimo de erros e repetições, aumentando a motivação para realizar os passos dos programas de ensino. No início do atendimento, as crianças demonstravam desinteresse por atividades no formato lápis e papel, similares às utilizadas em sala de aula, apresentando comportamentos de desviar o olhar, conversar sobre outros assuntos e dizer "não sei". No caso de crianças que apresentam dificuldades de aprendizagem, erros na leitura e escrita podem resultar, no contexto escolar e familiar, em consequências (e.g., desaprovação verbal, indicação visual do erro com um " $X$ " ou nota vermelha) que diminuem as ocorrências de interação com material verbal impresso. Durante a exposição a estas situações, uma resposta como dizer "não sei", resulta na interrupção da atividade, um comportamento de fuga, o que sugere características aversivas da tarefa. Ao longo do atendimento, ler e escrever foram associados com brincadeiras, situações de descontração e com diferentes contextos e usos funcionais, o que resultou em participação ativa em tarefas com lápis e papel, não apenas durante as sessões, mas também em casa e na escola, conforme relato dos familiares.

O uso do computador para o ensino de leitura de palavras com sílabas simples foi também relevante na medida em que constituía uma novidade e era utilizado como recurso para a apresentação de tarefas de curta duração, que demandavam participação ativa e proporcionavam alta frequência de apreciações positivas do desempenho da criança.

$\mathrm{Na}$ avaliação do repertório de entrada, observou-se que as crianças eram capazes de copiar com perfeição palavras impressas. A cópia de palavras e frases é uma atividade comumente utilizada em sala de aula. $\mathrm{O}$ uso frequente desta tarefa é fundamentado na crença de que se a criança consegue escrever corretamente, copiando o modelo, ela também será capaz de ler. Entretanto, estudos mostram que a leitura e a escrita são repertórios independentes, mas que em determinadas situações podem se tornar interdependentes (Lee \& Pegler, 1982).

Os programas utilizados no presente estudo destinavam-se a ensinar a leitura de palavras isoladas e a cópia com resposta construída, não sendo, portanto, ensinada de maneira explícita a escrita manuscrita. Ao longo dos atendimentos, foi observado aumento na precisão dos desempenhos de construção de palavras e 
de escrita manuscrita de palavras de ensino e de recombinação em situação de ditado após as crianças aprenderem a ler e construir um conjunto amplo de palavras (simples e complexas), o que é coerente com os resultados obtidos por Hanna e cols. $(2004 ; 2002)$. Pode-se sugerir também que o aumento da precisão da escrita manuscrita foi influenciado pela exposição a atividades lúdicas que requeriam modalidades diferentes de escrita: construir palavras em situação de ditado ou de cópia.

A realização de apenas uma sessão por semana tornou o atendimento muito longo, mas não comprometeu o desempenho das crianças nos programas de ensino. A leitura de palavras de recombinação aumentou com a exposição a cada passo, o que sugere interação entre os procedimentos de ensino utilizados no atendimento, incluindo as atividades lúdicas, e a história de exposição ao material impresso (letras, palavras, frases, livros) proporcionada na escola. Outro fator relevante foi o fato de que, mesmo não sendo bem sucedidas com os procedimentos de alfabetização utilizados na escola, as crianças iniciaram o atendimento dominando algumas relações condicionais descritas na rede de repertórios verbais tais como nomeação de figuras (BD), selecionar figura correspondente à palavra ditada $(\mathrm{AB})$, e escrever diante de palavras impressas (CE); identificação e nomeação de vogais e de algumas consoantes; e outros desempenhos relevantes (e.g., direção do olhar da esquerda para a direita, escrever no espaço delimitado por linha). Estes comportamentos contribuíram para a aprendizagem verificada ao longo do atendimento.

A avaliação do desempenho das crianças nas atividades que envolviam leitura de frases, pequenos textos e livros, não foi realizada devido à ausência de registros sistemáticos (e.g., filmagem das sessões) $\mathrm{e}$ medidas padronizadas. Estas atividades foram realizadas após o ensino de um conjunto amplo de palavras simples, cujas partes (sílabas e letras) eram partes constituintes das palavras complexas, e demandavam interação constante com o instrutor. Era necessário fornecer reforços sociais frequentes para desempenhos corretos ou que gradualmente se aproximavam da leitura fluente ou escrita manuscrita precisa. Conforme observações assistemáticas, o número de dicas verbais e o uso de modelos de pronúncia e de entonação corretas, por parte do instrutor, e a leitura pausada (palavra por palavra) das crianças diminuíram ao longo das sessões. Também se pode sugerir que a melhora na competência das crianças para construir palavras em situação de ditado, demonstrada nas avaliações realizadas no programa de ensino de palavras simples, influenciou o desempenho de escrever respostas a perguntas sobre pequenos textos.

O progresso nos desempenhos de leitura e escrita das crianças ao longo das sessões de intervenção mostra a relevância do paradigma de equivalência e da utilização de resultados de pesquisas empíricas na elaboração de estratégias de intervenção para crianças com história de fracasso ou dificuldade no processo de alfabetização. Entretanto, tais resultados devem ser analisados com cautela uma vez que não permitem identificar o efeito independente dos programas de ensino de leitura e das atividades lúdicas. Além disso, deve-se também considerar a influência do método de ensino utilizado nas escolas. Contudo, a metodologia utilizada no presente estudo permite analisar, de maneira sistemática, o efeito global do programa de intervenção proposto.

Outro aspecto a ser considerado é a importância de observações efetuadas no contexto de atendimentos individualizados para a realização de futuros estudos empíricos para investigar variáveis que influenciam a aquisição da leitura e escrita. $\mathrm{O}$ efeito dos programas de ensino de leitura e das atividades lúdicas, evidenciado no presente estudo, sugere a necessidade de elaboração de programas de ensino de leitura de unidades textuais maiores (e.g., frases, pequenos textos e livros) e a realização de pesquisas a fim de identificar condições mais adequadas para o ensino de tais unidades textuais. Para o contexto clínico, mais especificamente, uma contribuição da metodologia utilizada é o destaque para o planejamento de estratégias de intervenção, para crianças com dificuldades de aprendizagem no período da alfabetização, ajustadas de acordo com o repertório inicial de cada uma delas e modificadas sempre que ocorrerem erros e que a criança demonstrar que domina parcialmente ou ainda não aprendeu os desempenhos necessários para realizar uma determinada tarefa.

\section{REFERÊNCIAS}

Araújo, C. H., \& Luzio, N. (2005). Avaliação da educação básica: Em busca de qualidade e equidade no Brasil. Brasília: INEP/MEC.

de Rose, J. C. (1993). Classes de estímulos: Implicações para uma análise comportamental da cognição. Psicologia: Teoria $e$ Pesquisa, 9, 283-303.

de Rose, J. C., de Souza, D. G., \& Hanna, E. S. (1996). Teaching reading and spelling: Exclusion and stimulus equivalence. Journal of Applied Behavior Analysis, 29, 451-469.

de Rose, J. C., de Souza, D. G., Rossito, A. L., \& de Rose, T. M. S. (1992). Stimulus equivalence and generalization in reading after matching to sample by exclusion. Em S. C. Hayes \& L. J. Hayes (Orgs.), Understanding verbal relations: The second 
and third international institutes on verbal relations (pp. 6982). Reno, NV: Context Press.

de Souza, D. G., de Rose, J. C., Hanna, E. S., Calcagno, S., \& Galvão, O. F. (2004). Análise comportamental da aprendizagem de leitura e escrita e a construção de um currículo suplementar. Em M. M. C. Hubner \& M. Marinotti (Orgs.), Análise do comportamento para a educação: Contribuições recentes (pp. 177-203). Santo André, SP: ESETec.

Dixon, L. S. (1977). The nature of control by spoken words over visual stimulus selection. Journal of the Experimental Analysis of Behavior, 27, 433-442.

Hanna, E. S., de Souza, D. G., de Rose, J. C., \& Fonseca, M. (2004). Effects of delayed constructed-response identity matching on spelling of dictated words. Journal of Applied Behavior Analysis, 37(2), 223-227.

Hanna, E. S., de Souza, D. G., de Rose, J. C., Quinteiro, R. S., Campos, S. N. M., Alves, \& M., Siqueira, A. (2002) Aprendizagem de construção de palavras e seus efeitos sobre o desempenho em ditado: Importância do repertório de entrada. Arquivos Brasileiros de Psicologia, 54(3), 255-273.

Hanna, E. S., Melo, R. M, \& Albuquerque, A. R. (1999). Desenvolvimento infantil e alfabetização. Em M. G. T. Paz \& A. Tamayo (Orgs.), Escola, saúde e trabalho: Estudos psicológicos (pp. 71-100). Brasília: Editora UnB.

Instituto Nacional de Estudos e Pesquisas Educacionais. (2006). Sinopse estatística da educação básica: Censo escolar 2005. Brasília: INEP/MEC.

Lee, V. L., \& Pegler, A. M. (1982). Effects on spelling of training children to read. Journal of the Experimental Analysis of Behavior, 37, 311-322.

Marinotti, M. (1997). Psicopedagogia comportamental. Em M. Delitti (Org.), Sobre comportamento e cognição: Vol. 2. A prática da análise do comportamento e da terapia cognitivocomportamental (pp. 308-321). Santo André, SP: ARBytes.

Matos, M. A., Hubner, M. M., \& Peres, W. (1997). Leitura generalizada: Procedimentos e resultados? Em R. A. Banaco
(Org.), Sobre comportamento e cognição: Vol. 1. Aspectos teóricos, metodológicos e de formação em análise do comportamento e terapia cognitivista (pp. 470-487). Santo André, SP: ARBytes.

Melchiori, L. E., de Souza, D. G., \& de Rose, J. C. (2000). Reading, equivalence and recombination of units: A replication with students with different learning histories. Journal of Applied Behavior Analysis, 33, 97-100.

Meyer, S. B. (1997). O conceito de análise funcional. Em M. Delitti (Org.), Sobre comportamento e cognição: Vol. 2. A prática da análise do comportamento e da terapia cognitivocomportamental (pp. 31-36). Santo André, SP: ARBytes.

Nunes, A. N. A. (1990). Fracasso escolar e desamparo aprendido. Psicologia: Teoria e Pesquisa, 6(2), 139-154.

Rosa Filho, A. B. R., de Souza, D. G., de Rose, J. C., Fonseca, M. L., \& Hanna, E. S. (1998). Programa de leitura: Software para ensino de habilidades básicas de leitura e escrita [Software sem registro de patente].

Sidman, M. (1971). Reading and auditory-visual equivalences. Journal of Speech and Hearing Research, 14, 4-13.

Sidman, M. (1994). Equivalence relations and behavior: A research history. Boston, MA: Authors Cooperative.

Sidman, M., \& Tailby, W. (1982). Conditional discrimination $v s$ matching-to-sample: An expansion of the testing paradigm. Journal of the Experimental Analysis of Behavior, 37, 5-22.

Skinner, B. F. (1957). Verbal behavior. Englewood Cliffs, NJ: Prentice-Hall.

Stromer, R., Mackay, H. A., \& Stoddard, L. T. (1992). Classroom applications of stimulus equivalence technology. Journal of Behavioral Education, 2, 225-256.

Recebido: $29 / 08 / 2007$

Última revisão: 03/09/2008

Aceite final: 30/03/2009

\section{Notas:}

1 De acordo com dados do Instituto Nacional de Estudos e Pesquisas Educacionais do MEC referentes ao ano de 2005, 25\% dos alunos da $1^{\text {a }}$ série do Ensino Fundamental foram reprovados ou abandonaram o sistema escolar (INEP, 2006). Outro dado que merece atenção é que a média do Brasil em proficiência em leitura na $4^{\mathrm{a}}$ série do Ensino Fundamental está 31 pontos abaixo do mínimo considerado satisfatório (Araújo \& Luzio, 2005).

2 A coleta de dados foi realizada no período de 2002 a 2003, antes da nova redação da LDB, dada pela Lei 11.274, de 2006, que ampliou o Ensino Fundamental para 9 anos. Dessa forma, a $1^{\text {a }}$ série mencionada corresponde ao atual $2^{\circ}$ ano do Ensino Fundamental.

\section{Sobre as autoras:}

Raquel Maria de Melo: Doutora em Psicologia pela Universidade de Brasília; docente do Departamento de Processos Psicológicos Básicos do Instituto de Psicologia da Universidade de Brasília.

Patrícia Serejo: Psicóloga clínica infantil e doutoranda do Programa de Pós-Graduação em Ciências do Comportamento do Departamento de Processos Psicológicos Básicos do Instituto de Psicologia da Universidade de Brasília.

Endereço para correspondência: Departamento de Processos Psicológicos Básicos/Instituto de Psicologia, Universidade de Brasília Campus Universitário Darci Ribeiro - 70910-900 Brasília/DF. Endereço eletrônico: melo.rm@gmail.com. 